\title{
Nota Científica \\ Posição de semeadura na emergência e desenvolvimento inicial de plântulas de baru
}

\author{
Alan Mario Zuffo', Ana Paula Sousa Jesus², Saulo Gabriel de Faria Dias² \\ 'Universidade Federal de Lavras, Campus Universitário, CEP 37200-000, Lavras, MG, Brasil \\ ${ }^{2}$ Universidade do Estado de Mato Grosso, Campus de Nova Xavantina, BR-158, Km 148, CEP 78690-000, Nova Xavantina, MT, Brasil
}

\author{
"Autor correspondente: \\ alan_zuffo@hotmail.com \\ Dipteryx alata Vog \\ Emergência \\ Sementes \\ Fruto do Cerrado \\ Index terms: \\ Dipteryx alata Vog \\ Emergency \\ Seeds \\ Cerrado fruit
}

Termos para indexação:

\begin{abstract}
Resumo - Objetivou-se com este trabalho avaliar a influência da posição de sementes do baru, na emergência e no desenvolvimento inicial de plântulas. O ensaio foi realizado em casa de vegetação em delineamento experimental de blocos ao acaso, com cinco tratamentos (posição de semeio), com quatro repetições. As posições foram: A - hilo para cima, B - hilo para baixo, C - hilo e rafe de lado, D - rafe na horizontal para cima, E - rafe na horizontal para baixo. Foram avaliados a emergência, o índice de velocidade de emergência, a altura de plântulas (AP), o diâmetro do coleto (DC), o comprimento radicular, a fitomassa seca da parte aérea (FSPA), a fitomassa seca radicular (FSR), as relações AP/DC e FSPA/FSR e o índice de qualidade de Dickson. A emergência e o desenvolvimento inicial das plântulas de baru foram influenciados pela posição de semeadura. As sementes depositadas com o hilo para baixo proporcionaram melhores resultados.
\end{abstract}

Histórico do artigo: Recebido em 26/01/2014 Aprovado em 15/09/2014 Publicado em 10/10/2014

doi: 10.4336/2014.pfb.34.79.650

\section{Sowing on the emergence and early development of seedlings o baru}


O baru [Dipteryx alata Vog., Fabaceae] é uma espécie florestal nativa, tendo importância para uso como madeira, para alimentação e reflorestamento, dentre outros. Os frutos do baru são utilizados para a fabricação de alimentos humanos, devido aos altos valores de proteínas, zinco e ferro (Fernandes et al., 2010; Sousa et al., 2011), apresentando, valor ecológico, econômico e social (Arakaki et al., 2009).

A coleta dos frutos é uma importante atividade socioeconômica, por gerar renda para muitas comunidades rurais que praticam o agroextrativismo. Entretanto, com o avanço da agropecuária sobre o Cerrado, há redução dos indivíduos dessa espécie, tornando cada vez mais difícil sua coleta (Paiva Sobrinho et al., 2010). Nesse cenário, a recomposição de áreas com essa espécie tornase oportuna, sendo importante produzir mudas com alta qualidade e de baixo custo.

Para a produção de mudas de uma cultura com potencial econômico são necessárias informações básicas sobre a sanidade das sementes, substratos, composição e volume de adubos, balanço nutricional adequado (Hartmann et al., 2002) e a posição da semente na semeadura (Martins et al., 1999).

Uma semente depositada na posição correta proporciona rápida germinação e velocidade de emergência das plântulas. Durante o processo germinativo, a semente requer a realização de movimentos rotatórios dos cotilédones sob o solo, o que resulta em um menor tempo de permanência das mudas no viveiro (Martins et al., 1999; Carvalho \& Nakagawa, 2000), além de um menor desgaste fisiológico, ocasionado pelo menor consumo de energia para o hipocótilo movimentar-se durante a emergência.

Com relação ao desenvolvimento de plântulas florestais, cada espécie tem a posição adequada para o semeio. Por exemplo, Santos et al. (2009) verificaram que a emergência e o índice de velocidade de emergência de plântulas de cedro [Cedrela fissilis L.] foi mais rápida quando a semeadura foi realizada com o hilo para baixo. Para Silva et al. (2007), o posicionamento mais adequado das sementes de açaí [Euterpe oleracea Mart.] é com a rafe perpendicular ao substrato e o poro germinativo voltado para cima.

Dessa forma, estudos básicos sobre a posição de semeadura do baru são necessários, tendo em vista a escassez de material na literatura e a importância econômica da planta. Objetivou-se com este trabalho avaliar a influência da posição de sementes do baru, na emergência e no desenvolvimento inicial de plântulas.

O ensaio foi realizado na Fazenda União, no Município de Nova Xavantina, MT (14 ${ }^{\circ} 50^{\prime} 41^{\prime \prime S}$, $52^{\circ} 22^{\prime} 49^{\prime \prime} \mathrm{W}$, com altitude média de $290 \mathrm{~m}$ ), durante o período 24/08/2013 a 21/09/2013, em ambiente protegido a $50 \%$ de luminosidade. O clima da região é do tipo Aw, segundo a classificação climática global de Köppen, com duas estações bem definidas, sendo uma seca, de maio a setembro, e outra chuvosa, de outubro a abril. Os dados climáticos foram coletados na estação meteorológica do Instituto Nacional de Meteorologia (INMET) e encontram-se na Figura 1.

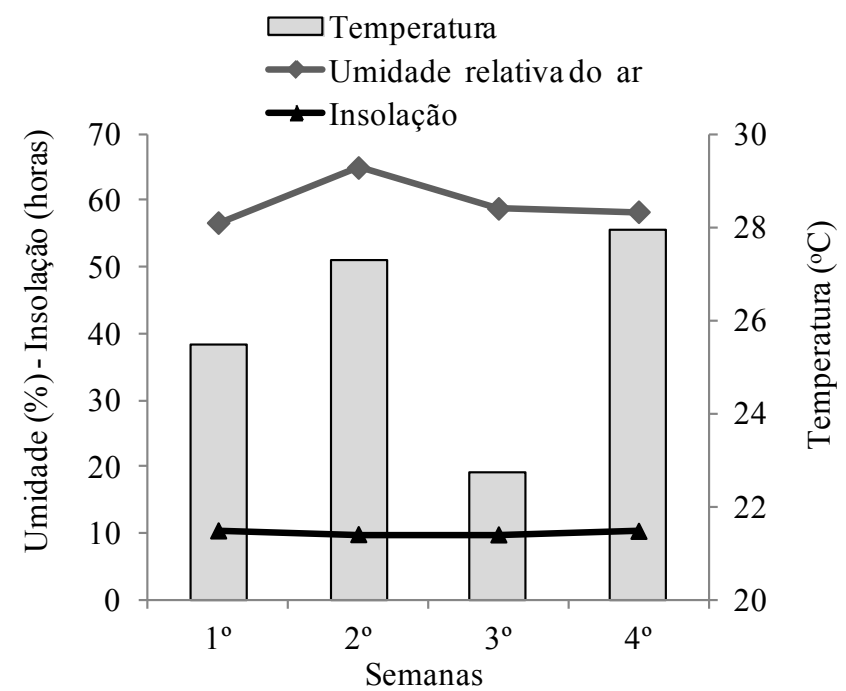

Figura 1. Temperatura média, umidade relativa do ar e insolação, no período 24/08/2013 a 21/09/2013 (Fonte: INMET - estação de Nova Xavantina, MT).

O substrato para a produção de mudas foi constituído de uma mistura de Latossolo Vermelho distrófico, esterco bovino curtido e casca de arroz natural, nas proporções de 6:3:1, respectivamente. O substrato não foi suplementado com adubação química. A homogeneização da mistura do substrato foi realizada manualmente e em seguida foi colocado em sacolas de plástico, com capacidade de $700 \mathrm{~cm}^{3}(21 \mathrm{~cm} \times 11 \mathrm{~cm})$. O solo foi retirado na camada de $0-10 \mathrm{~cm}$ de profundidade, em uma área de cultivo de soja. Resultados da análise química antes da instalação do experimento encontram-se na Tabela 1. 
Tabela 1. Composição química do solo Latossolo Vermelho distrófico $(0-10 \mathrm{~cm})$ antes da instalação do experimento na Fazenda União, Nova Xavantina, MT.

\begin{tabular}{|c|c|c|c|c|c|c|c|c|c|c|}
\hline \multirow{2}{*}{$\begin{array}{c}\mathrm{pH} \\
\mathrm{CaCl}_{2}\end{array}$} & $\mathrm{Ca}^{2+}$ & $\mathrm{Mg}^{2+}$ & $\mathrm{Al}^{3+}$ & $\mathrm{H}^{+}+\mathrm{Al}^{3+}$ & SB & CTC & $\mathrm{P}$ & $\mathrm{K}$ & \multirow{2}{*}{$\begin{array}{c}\mathrm{MO} \\
\mathrm{g} \mathrm{kg}^{-1}\end{array}$} & \multirow{2}{*}{$\begin{array}{l}\mathrm{V} \\
\%\end{array}$} \\
\hline & \multicolumn{6}{|c|}{---------------- $\mathrm{cmol}_{\mathrm{c}} \mathrm{dm}^{-3}$-------------- } & \multicolumn{2}{|c|}{$--m g d^{-3}--$} & & \\
\hline 5,40 & 1,14 & 0,60 & 0,00 & 2,90 & 1,90 & 4,80 & 2,00 & 65,00 & 6,40 & 39,70 \\
\hline
\end{tabular}

As sementes para a realização do experimento foram coletadas de frutos oriundos de plantas nativas do Município de Nova Xavantina, MT, conduzidas sem manejo específico quanto à adubação, irrigação, poda e controle fitossanitário. Após a colheita, os frutos foram levados ao laboratório para seleção e uniformização, onde foi promovida a extração manual do endocarpo e as sementes foram retiradas para o plantio.

O delineamento experimental utilizado foi o de blocos ao acaso, com cinco tratamentos (posição de semeio) e, com quatro repetições. As posições foram: A - hilo para cima, B - hilo para baixo, C - hilo e rafe de lado, D - rafe na horizontal para cima, E - rafe na horizontal para baixo, sendo todas as semeaduras em profundidade de $2 \mathrm{~cm}$.

$\mathrm{O}$ grau de umidade das sementes foi determinado pelo método da estufa a $105{ }^{\circ} \mathrm{C} \pm 3{ }^{\circ} \mathrm{C}$ por 24 horas (Brasil, 2009).

Aos 15 dias após a semeadura iniciou-se diariamente a avaliação do número de plântulas emergidas, até aos 28 dias, sendo determinados a percentagem de emergência e o índice de velocidade de emergência (IVE) de cada tratamento. Para o cálculo do IVE adotou-se a fórmula de Maguire (1962).

Também aos 28 dias após a semeadura foram avaliadas: altura de plântula $(\mathrm{cm})$ - determinada da superfície do solo à inserção da última folha com auxílio de uma régua milimetrada; diâmetro do coleto $(\mathrm{cm})$ - mensurado na altura do colo da planta por meio de leituras com utilização de paquímetro digital Clarke ${ }^{\mathbb{B}}$; comprimento da maior raiz $(\mathrm{cm})$, denominada de raiz pivotante, com uma régua milimetrada. As plântulas foram separadas em parte aérea e sistema radicular, acondicionadas em sacos de papel e levadas para estufa de circulação forçada por 72 horas a $60^{\circ} \mathrm{C}$ até a obtenção da massa constante, visando a determinação da massa seca de raízes e parte aérea $(\mathrm{g})$.

A partir dessas avaliações, determinou-se a fitomassa seca total (FST) e calcularam-se os índices morfológicos: relação altura $(\mathrm{cm}) /$ diâmetro do coleto $(\mathrm{mm})(\mathrm{AP} / \mathrm{DC})$; fitomassa seca da parte aérea/fitomassa seca das raízes
(FSPA/FSR) e índice de qualidade de Dickson (IQD) (Dickson et al., 1960), através da equação:

ID = fitomassa seca total/(altura/diâmetro) + (fitomassa seca parte aérea/fitomassa seca raízes).

As médias foram submetidas à análise de variância, e quando significativas agrupadas pelo critério de ScottKnott a 5\% de significância, utilizando-se o programa estatístico SISVAR (Ferreira, 2011).

$\mathrm{O}$ grau de umidade das sementes de baru encontrava-se em torno de $9,7 \%$. Com exceção da relação AP/DC, todos os demais parâmetros foram influenciados significativamente pela posição de semeadura das sementes de baru (Tabela 2).

As posições de semeadura B (hilo para baixo), C (hilo e rafe de lado), e D (rafe na horizontal para cima) apresentaram maior emergência e índice de velocidade de emergência (Figura 2). Esses resultados corroboram parcialmente aos obtidos por Sousa et al. (2007). Esses autores verificaram que as posições das sementes de moringa [Moringa oleifera Lam.] com o ápice para cima e deitadas favoreceram o índice de velocidade de emergência e a massa fresca das plântulas.

Apesar das posições B (hilo para baixo), C (hilo e rafe de lado), e D (rafe na horizontal para cima) não diferirem estatisticamente, verificou-se que a posição $\mathrm{B}$ (hilo para baixo) foi numericamente superior às demais, provavelmente, ao fato do menor movimento da radícula para se fixar no substrato. Dessa forma, durante a emergência há o menor gasto da reserva contida na semente, resultando em maior energia para que a plântula se desenvolva. Esse fato é ainda reforçado à medida que se compara com os demais parâmetros avaliados, no qual, observou-se que a posição B (hilo para baixo) apresentou valores mais altos para altura de plântulas, diâmetro do coleto, comprimento radicular, fitomassa seca da parte aérea, fitomassa seca radicular, relação AP/ DC, FSPA/FSR e para o índice de qualidade de Dickson (Tabela 3). Esses resultados se assemelham aos obtidos para sementes de tucumã [Astrocaryum aculeatum Meyer] (Elias et al., 2006), guapuruvu [Schizolobium parahyba (Vell.) S.F. Blake] (Martins et al., 2012), e 
divergem dos encontrados nas sementes de bacabinha [Oenocarpus mapora Karsten] (Nascimento et al., 2002).

Para Fonseca et al. (2002) o índice de qualidade de Dickson é um bom indicador da qualidade da muda, uma vez que considera o equilíbrio da distribuição de biomassa da muda e sua robustez, resultando em melhor desenvolvimento inicial e qualidade final das mudas. De maneira geral, os maiores valores do índice de qualidade de Dickson indicam plântulas de maior vigor e, consequentemente, melhor qualidade. Desta forma, considerando a posição B (hilo para baixo) como a ideal, constata-se que os maiores valores de todos os parâmetros foram verificados nessa posição, enquanto que os menores valores foram obtidos na posição A (hilo para cima) e E (rafe na horizontal para baixo).
O baru, da família Fabaceae, apresenta germinação do tipo epígea, o que significa que durante o processo germinativo os cotilédones ultrapassam a superfície do solo. Sendo assim, por não necessitar de movimentos da radícula para se fixar no substrato, a plântula cresce próxima ao hilo. Com isso, há um menor desgaste fisiológico para que o cotilédone consiga atingir a superfície do solo, tendo maior reserva para suprir posteriormente o desenvolvimento da plântula. A plântula passa a ser autotrófica quando inicia a fotossíntese, processo este que permite à planta produzir o próprio alimento de forma gradativa. Porém, nos primeiros estágios é dependente apenas das reservas armazenadas pela semente (Marcos Filho, 2005).

Tabela 2. Análise de variância dos dados relativos à emergência $(\mathrm{E})$, índice de velocidade de emergência (IVE), altura de plântulas (AP), diâmetro do coleto (DC), comprimento radicular (CR), fitomassa seca parte aérea (FSPA), fitomassa seca radicular (FSR), relação AP/DC, FSPA/FSR e o índice de qualidade de Dickson (IQD), obtidas no ensaio de posição das sementes de baru [Dipteryx alata Vog]. Nova Xavantina, MT, 2013.

\begin{tabular}{|c|c|c|c|c|c|c|}
\hline \multirow{2}{*}{$\begin{array}{c}\text { Fontes de } \\
\text { variação }\end{array}$} & \multirow{2}{*}{ GL } & \multicolumn{5}{|c|}{ Quadrados médios } \\
\hline & & $\mathbf{E}$ & IVE & $\mathbf{A P}$ & DC & CR \\
\hline Posição & 4 & $1279,575000 *$ & $0,161003 * *$ & $3,581250 * *$ & $1,033338 * *$ & $5,569875 * *$ \\
\hline Blocos & 3 & 145,200000 & 0,010527 & 0,497833 & 0,006300 & 1,325458 \\
\hline Resíduos & 12 & 372,075000 & 0,005514 & 0,249917 & 0,008238 & 0,580875 \\
\hline CV $(\%)$ & & 26,21 & 16,63 & 10,36 & 2,48 & 7,92 \\
\hline \multirow{2}{*}{$\begin{array}{c}\text { Fontes de } \\
\text { variação }\end{array}$} & \multirow{2}{*}{ GL } & \multicolumn{5}{|c|}{ Quadrados médios } \\
\hline & & FSPA & FSR & AP/DC & FSPA/FSR & IQD \\
\hline Posição & 4 & $0,058015^{* *}$ & $0,009287 * *$ & $0,030796^{\mathrm{ns}}$ & $0,625472 * *$ & $0,006624 * *$ \\
\hline Blocos & 3 & 0,000322 & 0,000017 & 0,034140 & 0,030188 & 0,000029 \\
\hline Resíduos & 12 & 0,000233 & 0,000094 & 0,024236 & 0,030860 & 0,000055 \\
\hline CV $(\%)$ & & 7,51 & 7,71 & 11,85 & 11,59 & 6,70 \\
\hline
\end{tabular}

** e * significativo a 1 e $5 \%$ respectivamente, pelo teste $\mathrm{F}$.

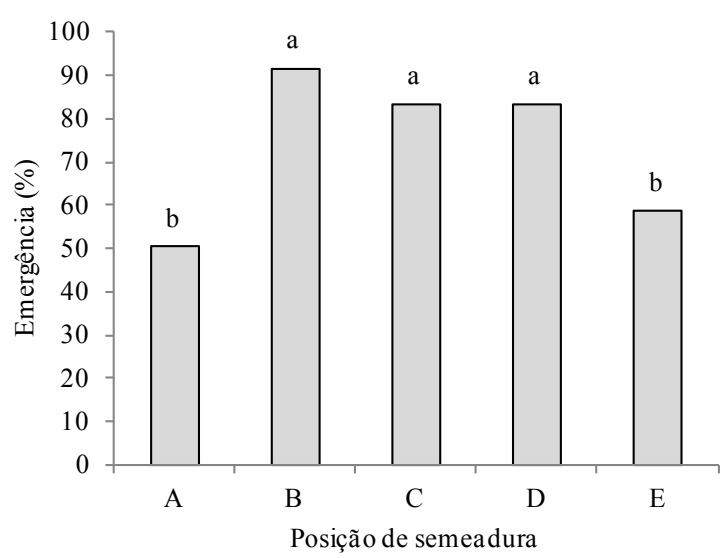

A

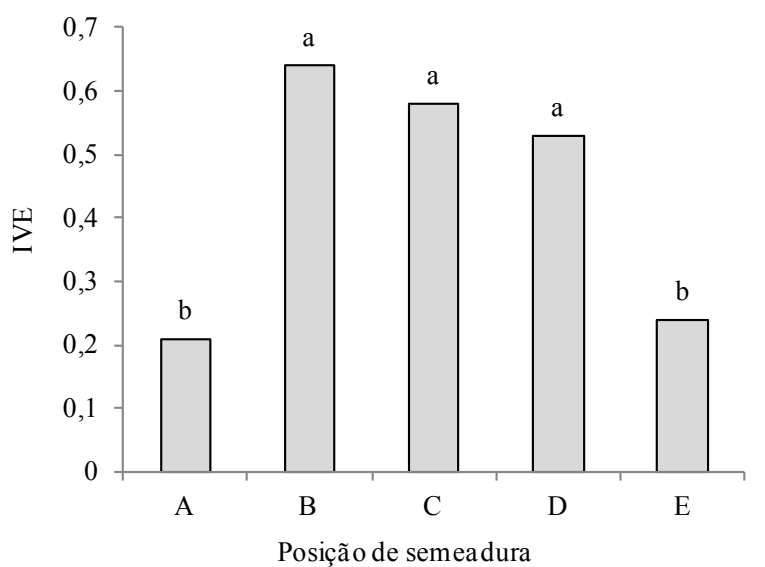

Figura 2. Percentagem de emergência e índice de velocidade de emergência (IVE) de plântulas de baru [Dipteryx alata Vog] em função da posição de semeadura $(\mathrm{A}=$ hilo para cima; $\mathrm{B}=$ hilo para baixo; $\mathrm{C}=$ hilo e rafe de lado; $\mathrm{D}=$ rafe na horizontal para cima; E = rafe na horizontal para baixo). Nova Xavantina, MT, 2013. 
Tabela 3. Altura de plântulas (AP), diâmetro do coleto (DC), comprimento radicular (CR), fitomassa seca da parte aérea (FSPA), fitomassa seca radicular (FSR), relação AP/DC, FSPA/FSR e índice de qualidade de Dickson (IQD) obtidos no ensaio de posição das sementes de baru [Dipteryx alata Vog], em Nova Xavantina, MT, 2013.

\begin{tabular}{c|cccccccc}
\hline \multirow{2}{*}{ Posição } & AP $(\mathbf{c m})$ & DC $(\mathbf{m m})$ & CR $(\mathbf{c m})$ & FSR (g) & FSPA (g) & AP/DC & FSPA/FSR & IQD \\
\hline A & $3,62 \mathrm{C}$ & $3,08 \mathrm{C}$ & $8,50 \mathrm{~B}$ & $0,06 \mathrm{C}$ & $0,07 \mathrm{D}$ & $1,15 \mathrm{~A}$ & $1,05 \mathrm{C}$ & $0,06 \mathrm{C}$ \\
$\mathrm{B}$ & $6,12 \mathrm{~A}$ & $4,34 \mathrm{~A}$ & $11,58 \mathrm{~A}$ & $0,17 \mathrm{~A}$ & $0,37 \mathrm{~A}$ & $1,41 \mathrm{~A}$ & $2,11 \mathrm{~A}$ & $0,15 \mathrm{~A}$ \\
$\mathrm{C}$ & $5,12 \mathrm{~B}$ & $3,77 \mathrm{~B}$ & $9,37 \mathrm{~B}$ & $0,15 \mathrm{~B}$ & $0,23 \mathrm{~B}$ & $1,35 \mathrm{~A}$ & $1,58 \mathrm{~B}$ & $0,13 \mathrm{~B}$ \\
$\mathrm{D}$ & $5,00 \mathrm{~B}$ & $3,84 \mathrm{~B}$ & $9,63 \mathrm{~B}$ & $0,15 \mathrm{~B}$ & $0,23 \mathrm{~B}$ & $1,30 \mathrm{~A}$ & $1,51 \mathrm{~B}$ & $0,13 \mathrm{~B}$ \\
$\mathrm{E}$ & $4,35 \mathrm{C}$ & $3,22 \mathrm{C}$ & $9,00 \mathrm{~B}$ & $0,07 \mathrm{C}$ & $0,10 \mathrm{C}$ & $1,32 \mathrm{~A}$ & $1,29 \mathrm{C}$ & $0,07 \mathrm{C}$ \\
\hline
\end{tabular}

Médias seguidas de letras iguais nas colunas não diferem entre si pelo teste Scott-Knott a $5 \%$.

Alves et al. (2014) também observaram que a posição de semeadura pode influenciar no conteúdo de massa seca das plântulas de fava [Phaseolus lunatus L.], comprovando que a semeadura na posição correta favorece o desenvolvimento de plântulas mais vigorosas e com maior capacidade de sobrevivência.

Ao analisar as variáveis relacionadas ao sistema radicular, constata-se diferença entre as posições avaliadas, com reduções entre a posição A (hilo para cima) e posição B (hilo para baixo) de $26,59 \%$ e $64,70 \%$, respetivamente, para o comprimento radicular e fitomassa seca radicular (Tabela 3). Para Taiz \& Zeiger (2009) a redução nessas variáveis reflete em forte influência no desenvolvimento da planta, pois as raízes são responsáveis pela absorção de água e dos nutrientes.

A emergência e o desenvolvimento inicial das plântulas de baru foram influenciados pela posição de semeadura. Assim, para favorecer a emergência de plântulas de baru, proporcionando melhor desenvolvimento inicial e índice de qualidade de Dickson, o plantio das sementes deve ser realizado na posição B (hilo para baixo).

\section{Agradecimentos}

Os autores expressam seus agradecimentos ao $\mathrm{CNPq}$ (Conselho Nacional de Desenvolvimento Científico e Tecnológico), pela concessão da bolsa de Doutorado, à Universidade do Estado de Mato Grosso e à Universidade Federal de Lavras, pelo apoio logístico.

\section{Referências}

Alves, A. U.; CARDoso, E. A. de; AlEXANDRE, T. F.; CAVALCANTE, Í. H. L.; BECKMANN-CAVALCANTE, M. Z. Emergência de plântulas de fava em função de posições e profundidades de semeadura. Bioscience Journal, Uberlândia, v. 30, n. 1, p. 33-42, 2014.
ARAKAKI, A. H.; SCHEIDT, G. N.; PORTELA, A. C.; ARRUDA, E. J. de; COSTA, R. B. da. O baru (Dipteryx alata Vog.) como alternativa de sustentabilidade em área de fragmento florestal do Cerrado, no Mato Grosso do Sul. Interações, Campo Grande, v. 10, n. 1, p. 31-39, 2009.

BRASIL. Ministério da Agricultura, Pecuária e Abastecimento. Secretaria de Defesa Agropecuária. Regras para análise de sementes. Brasília, DF, 2009. 398 p.

CARVALHO, N. M.; NAKAGAWA, J. Sementes: ciência, tecnologia e produção. 4. ed. Jaboticabal: FUNEP, 2000. 429 p.

DICKSON, A.; LEAF, A. L.; HOSNER, J. F. Quality appraisal of white spruce and white pine seedling stock in nurseries. Forest Chronicle, Ottawa, v. 36, n. 1, p. 10-13, 1960.

ELIAS, M. E. A.; FERREIRA, S. A. do N.; GENTIL, D. F. de O. Emergência de plântulas de tucumã (Astrocaryum aculeatum) em função da posição de semeadura. Acta Amazônica, Manaus, v. 36, n. 3, p. 385-388, 2006.

FERNANDES, D. C.; FREITAS, J. B.; CZEDER, L. P.; NAVES, M. M. V. Nutritional composition and protein value of the baru (Dipteryx alata Vog.) almond from the Brazilian Savanna. Journal of the Science of Food and Agriculture, New York, v. 90, n. 10, p. 1650-1655, 2010.

FERREIRA, D. F. Sisvar: a computer statistical analysis system. Ciência Agrotecnologia, Lavras, v. 35, n. 6, p. 1039-1042, 2011.

FONSECA, E. P.; VALÉRI, S. V.; MIGLIORANZA, E.; FONSECA, N. A. N.; COUTO, L. Padrão de qualidade de mudas de Trema micranta (L.) Blume, produzidas sob diferentes períodos de sombreamento. Revista Árvore, Viçosa, v. 26, n. 4 p. 515 - 523, 2002.

HARTMANN, H. T.; KESTER, D. E.; DAVIES JUNIOR, F. T.; GENEVE, R. L. Plant Propagation: principles and practices. 7. ed. New Jersey: Prentice Hall, 2002. 880 p.

MAGUIRE, J. D. Speed of germination aid in selection and evaluation for seeding emergence and vigor. Crop Sciense, Madison, v. 2, n. 2, p. 176-177, 1962.

MARCOS FILHO, J. Fisiologia de sementes de plantas cultivadas. Piracicaba: FEALQ, 2005. 495 p.

MARTINS, C. C.; BORGES, A. da S.; PEREIRA, M. T. G. Posição da semente na semeadura e tipo de substrato sobre a emergência e crescimento de plântulas de Schizolobium parahyba (Vell.) S.F. Blake. Ciência Florestal, Santa Maria, RS, v. 22, n. 4, p. 845-852, 2012. 
MARTINS, C. C.; NAKAGAWA, J.; BOVI, M. L. A. Efeito da posição da semente no substrato e no crescimento inicial das plântulas de Palmito-Vermelho (Euterpe espiritosantensis Fernandes - Palmae). Revista Brasileira de Sementes, Brasília, DF, v. 21, n. 1, p. 164-173, 1999.

NASCIMENTO, W. M. O.; OLIVEIRA, M. S. P.; CARVALHO, J. E. U.; MÜLLER, C. H. Influência da posição de semeadura na germinação, vigor e crescimento de plântulas de bacabinha (Oenocarpus mapora karsten - Arecaceae). Revista Brasileira de Sementes, Brasília, DF, v. 24, n. 1, p. 179-182, 2002.

PAIVA SOBRINHO, S.; LUZ, P. B. da; SILVEIRA, L. S. T.; RAMOS, D. T.; NEVES, L. G.; BARELLI, M. A. A. Substratos na produção de mudas de três espécies arbóreas do cerrado. Revista Brasileira de Ciências Agrárias, Recife, v. 5, n. 2, p. 238-243, 2010.

SANTOS, S. S.; MOURA, M. F.; GUEDES, R. S.; GONÇALVES, E. P.; ALVES, E. U.; MELO, P. A. F. R. Emergência de plântulas de Cedrela fissilis L. em função de diferentes posições e profundidades de semeadura. Biotemas, Florianopólis, v. 22, n. 4, p. 45-52, 2009.
SILVA, B. M. S.; MÔRO, F. V.; SADER, R.; KOBORI, N. N. Influência da posição e da profundidade de semeadura na emergência de plântulas de açaí (Euterpe oleracea Mart. - Arecaceae). Revista Brasileira de Fruticultura, Jaboticabal, v. 29, n. 1, p. 187-190, 2007.

SOUSA, A. G. de O.; FERNANDES, D. C.; ALVES, A. M.; FREITAS, J. B. de.; NAVES, M. M. V. Nutritional quality and protein value of exotic almonds and nut from the Brazilian Savanna compared to peanut. Food Research International, Guelph, v. 44, n. 7, p. 2319-2325, 2011.

SOUSA, A. H.; RIBEIRO, M. C. C.; MENDES, V. H. C.; MARACAJÁ, P. B.; COSTA, D. M. da. Profundidades e posições de semeadura na emergência e no desenvolvimento de plântulas de moringa. Revista Caatinga, Mossoró, v. 20, n. 4, p. 60, 2007.

TAIZ, L.; ZEIGER, E. Fisiologia vegetal. 4. ed. Porto Alegre: Artmed, 2009. 719 p. 